\title{
Sorptivity of self-compacting concrete containing fly ash and silica fume
}

\author{
H. Y. Leung, J. Kim, A. Nadeem, Jayaprakash Jaganathan, M. P. Anwar \\ School of Engineering
}

\section{Abstract}

This paper presents the surface water absorption of self-compacting concrete (SCC) containing fly ash and silica fume using sorptivity test. Ordinary Portland cement was partially replaced by various combinations of fly ash and silica fume. Test results show that the presence of fly ash and silica fume significantly reduce the surface water absorption of self-compacting concrete at a water-binder ratio of 0.38 . When only fly ash is used to partially replace Ordinary Portland cement, a more noticeable reduction in sorptivity is found when the fly ash content is greater than $20 \%$. The effect of combined use of fly ash and silica fume on reducing the water absorption and sorptivity is much more significant than using fly ash only. Moreover, it is noted that increasing the proportion of fly ash and silica fume leads to an enhanced reduction in water absorption. The addition of fly ash and silica fume, in general, increases the 28-day cube strength. However, there is no correlation between the compressive strength and the sorptivity in SCC achieved.

Original language

Pages (from-to)

Number of pages

Journal

Volume

State

\section{English}

$369-375$

7

Construction and Building Materials

113

Published - Jun 152016

Leung, H. Y., Kim, J., Nadeem, A., Jaganathan, J., \& Anwar, M. P. (2016). Sorptivity of selfcompacting concrete containing fly ash and silica fume. Construction and Building Materials, 113, 369-375. DOI: 10.1016/j.conbuildmat.2016.03.071 